\title{
The Primary Large Fourth Ventricular Schwannoma Removed by the Cerebellomedullary Fissure Approach. Case Report and Review of the Literature
}

Chen Li-Hua*, Ru-Xiang Xu, Wei Qun, Li Yun-Jun, Li Wen-De, Zhao Hao, Gao Jin-Bao and Yu Bin

The affiliated Bayi Brain Hospital, the Military General Hospital of Beijing PLA, Beijing, 100700, PR China

*Corresponding author: Chen Li-Hua, The affiliated Bayi Brain Hospital, the Military General Hospital of Beijing PLA, Beijing, 100700, PR China, Tel: 86-10-13801187508; E-mail: 13801187508@sinasn

Rec date: Dec 24, 2014, Acc date: Jan 07, 2015, Pub date: Jan 09, 2015

Copyright: (c) 2014 Chen Li-Hua, et al. This is an open-access article distributed under the terms of the Creative Commons Attribution License, which permits unrestricted use, distribution, and reproduction in any medium, provided the original author and source are credited.

\begin{abstract}
The objective of this study was to present a case of a solitary fourth intraventricular schwannoma with a review of the literature, and to analyzing the current theories of its origin and application of trancerebellomedullary fissure approach. The authors presented a primary intraventricle schwannoma occurring in the lateral recess of the fourth ventricle in a 53-year-old female. She presented with severe headache, dysphagia, horizontal nystagmus, ataxia and quadriparesis were detected on initial examination. Imaging studies showed a large mass in the fourth ventricle and a marked hydrocephalus. The tumor was removed by microsurgical dissection using the cerebellomedullary fissure approach at our Institution. Complete removal was achieved and no reccurrence was noted follow-up period of 8 months after surgery. To our knowledge, this is the ninth reported case schwannoma of fourth intraventricule in the literature, which is unrelated to the cranial nerves and cerebellar hemisphere parenchyma, blood vessel or to the dura, is extremely rare. The etiology and natural history of intraventricular schwannomas is not well understood. The presenting clinical, radiological and pathological features of this tumor are summarized. We have discussed the effectiveness of this approach for removal of bulky tumors of the fourth ventricle, the other cases reported in the literature are reviewed and the benefits and potential hazards of trancerebellomedullary fissure (T-CMF) approach. Intraventricular schwannomas are benign tumours that are amenable to complete surgical removal, having a good prognosis without the need of adjuvant therapy.
\end{abstract}

\section{Keywords: Intraventricular schwannoma; Fourth ventricle; Case Report}

Cerebellomedullary fissure; Microsurgical technique

\section{Introduction}

Schwannomas are generally benign tumors of the peripheral nerve sheath and account for $8 \%$ of all primary intracranial tumors [1,2]. Most intracranial schwannomas arise from the vestibular portion of the eighth cranial nerve and are more frequently found in middle-aged females, preferentially involving the superior vestibular branch of the acoustic nerve. Schwannomas have been reported from various unusual intracranial locations like cerebellum, ventricle, sella, brain stem, etc. [3-6]. Intraventricular schwannomas are an exceedingly rare tumors [5,7-21], with only eight fourth intraventricular schwannomas being described in the literature $[5,12,16,18,21-24]$. That, however, remains a challenge even for the most skillful surgeons because of the vicinity of important brainstem and cranial nerve structures involved and is particularly difficult for large intraventricular schwannomain of the fourth ventricule. Here, the authors report an extremely rare primary intraventricular schwannoma originating in the fourth ventricle where it did not have any attachment to the surrounding structures (cranianl nerve, blood vessel, cerebellar hemisphere parenchyma), this solitary schwannoma was removed using the cerebellomedullary fissure approach, and the pertinent literature is reviewed. The technique and benefits of transcerebellomedullary fissure approaches and the possible origins of this tumor in this unique location are also discussed.

\section{Signs and symptoms}

A previously healthy 53-year-old woman who was admitted to our neurosurgery department of Bayi Brain Hospital in Sept, 2012. She presented with clinical signs of intracranial hypertension, severe tussive headache that was associated to vomiting episodes during one month before he presented, intermittent episodic vomiting and visual obscuration, progressive hoarseness and diplopia, dysphagia and did not swallowing that insertion gastric canal is mandatory, progressively worsening generalized weakness result in lying the bed, memory disturbances and gait instability, moderately facial paresis accompanying with low nasolabial groove in the left-side, developed in the last five months before presentation. She was performed ventriculoperitoneal shunt in other hospital because of severe hydrocephalus, began to experience progressive slightly drowsy mentality and worsening vomiting 45 days prior to admission. She was also performed incision of tracheal due to pulmonary infection, excessive phlegm on account of severe dysphagia at 16 days before admission. There was no stigmata of a neurocutaneous syndrome and there was no history in her family of inheritable neurological disorder, such as neurofibromatosis.

\section{Examination}

On admission, the patient was slightly drowsy, bedridden and uncooperative neurological examination. The general physical 
Citation: Li-Hua C, Xu R-C, Qun W, Yun-Jun L, Wen-De L, et al. (2015) The Primary Large Fourth Ventricular Schwannoma Removed by the Cerebellomedullary Fissure Approach. Case Report and Review of the Literature. J Neurol Disord 3: 204. doi: $10.4172 / 2329-6895.1000204$

Page 2 of 9

examination was normal, heart, kidney and liver function was normal. No cutaneous pigmented lesions were identified. His routine biochemical and hematological parameters were also normal. The acuity and visual fields could not be performed becuase of uncooperation. Shunt latch was founded in the right forehead. There was features of increased intracranial pressure, funduscopy revealed bilateral papilledema. Detailed cranial nerve examination revealed slight bilateral horizontalis nystagmus and diplopia gazing either side, particularly with gaze to the left side, moderately left facial paresis with an asymmetrical smile. The dysarthric speech, a weak gag reflex, and apparent quadriparesis were detected on examination. Inspection of the left eye revealed a marked esotropia with an inability to abduct the eye beyond the midline and right side gaze. He had bilateral upper extremity dysmetria on finger-nose testing as well as dysdiadochokinesia, and ataxia of the lower extremities on heel-shin testing, respectively. Her deep tendon reflexes were accentuation in the bilateral lower extremities.

\section{Radiological examination}

Pre-operative computerized tomography (CT) scan of the brain identified an regular isointensity to hyperdense dorsal pontomedullary tumor, projecting into the fourth ventricle, third and lateral ventricles were moderately dilated. This tumor is a well-defined, solid-cytic lesion, the solid component of the lesion showed a plain tumor boundary (Figure 1), within the fourth ventricle, with associated hydrocephalus and had been performed ventriculoperitoneal shunt.
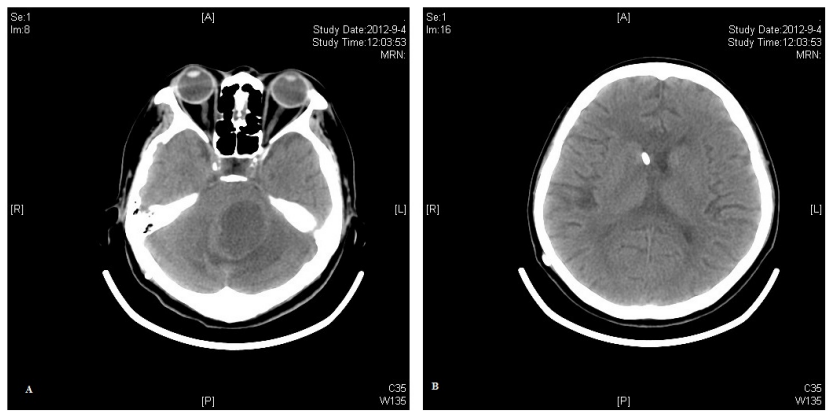

Figure 1: (A) Preoperative non-contrast enhanced axial CT scan showing the tumor location in the posterior fossa, occupying the forth ventricle, CT scan showing a marked homogeneous hypodense mass lesion with hyperdense tumor periphery in the fourth ventricle, accompanying with cerebellar hemisphere edema. (B) showing shunt tube located in the cornu frontale ventriculi lateralis on right side.

A magnetic resonance imaging (MRI) on a 3.0-tesla system showed a large mass, mixed solid-cystic lesion, filling in the fourth ventricle which was apparently heterogeneous enhanced with intravenous administration of gadolinium (Figure 2), $5.1 \mathrm{~cm} \times 5.3 \mathrm{~cm}$ in size, a bulky, space-occupying lesion of apparent intraventricular origin, appearing to compress the brainstem and cerebellum, and extending inferiorly into the upper cervical region. The axial T1-weighted MRI demonstrates center non-enhancing component of low signal intensity which was thought to represent a cystic component of the tumor, and peripheral iso to slightly hypointense signal with contrast enhancement after gadolinium diethylenetriamine pentaacetic acid (Gd-DTPA) injection. There was remarkably distortion of the brainstem, cerebellum, and fourth ventricle was filled with the mass. The sagittal T1-weighted MRI confirmed its location in the fourth ventricle, and demonstrated a heterogeneously enhancing lesion with a cystic component, displacing the brian stem. The tumor is an asymmetrical, solitary spherical tumor. The lesion had regular border with two components, the larger, periphery portion was nearly isointense to the cerebellum and the smaller, and center segment was slightly hypointense relative to CSF. The lesion included multiloculated cystic component and had a nodular portion that seemed to extend into cisterna magna, with perilesional oedema. The lesion is also found to be extending through the foramen magnum up to $\mathrm{C} 1$. The brainstem was displaced anteriorly and right side, the cerebellum was displaced posteriorly. This tumor was hypo- to isointense on axial T1-weighted image (T1-WI) (Figure 2A), mixed hyperintense lesion on T2-weighted image (T2-WI). It was mixed hyperintense on the T2-fluid attenuated inversion recovery (T2FLAIR) and occupying the all part of the 4th ventricle (Figure 2B), mixed hyperintense on the diffusion-weighted image (DWI) sequences (Figure 2C). It was iso- to hypointense on the T1- FLAIR (Figure 2D) and iso- to hyperintense on the T2-FLAIR (Figure 2E). The tumor was as asymmetrical and confounding peripheral enhancement on T1-WI (Figure 2F-H). These radiographic features and location of the tumor, in conjunction with the clinical findings, suggested a tentative diagnosis of fourth ventricular ependymoma. Other diagnostic considerations included exophytic brainstem astrocytoma, and choroid plexus papilloma or epidermoid.

\section{Surgical technique}

The patient was positioned between lateral decubitus and prone position, while the head was flexed and stretched backward. A posterior midline incision was made from inion to the spinous process of C3. The patient underwent a standard midline suboccipital craniectomy and C1 laminectomy. The cerebellomedullary fissure approach was used to perform the microsurgical excision. A tumor is safely removed by this approach with easy feeder or tumor bed controls. After the dura was opened, the bilateral cerebellar tonsils were retracted superolaterally and inferior vermis was chalasia, with the use of operating microscope, this eventually exposes a wide interior of the ventricle, revealing the solid-cystic portion of the tumor. This is a large, light brown and yellowish, firm and shiny tumour. It was encountered between the cerebellar hemispheres which extended inferiorly into the upper cervical region, appearing tumor originating from the floor of the fourth ventricle on the left side adjacent to facial colliculus. Once the cyst was opened, there was a gush of highly xanthochromic fluid. Solid portions of tumor, which were firm in consistency. The tumour's abundant feeding arteries were derived from the vertebral artery and posterior inferior cerebellar artery (PICA), but the most important feeders which had to be occluded to attain a good haemostasis originated from the PICA. The tumor did not appear to arise from any of the lower cranial nerves, and actually appeared to arise from the fourth ventricular floor on the left side. It was firmly rooted in the vicinity of the facial colliculus and did not have a uniformly tough consistency. With tiny tumor remaining firmly adherent to the floor of the fourth ventricle. Initial attempts to remove this residual tumor by bipolar coagulation, led to significant bradycardia as well as changes in somatosensory evoked potentials. Further complete microsurgical resection was performed through piecemeal removal of the tumour assisted by cavitron ultrasonic aspiration(CUSA) and laser knife. The dura was then closed in a 
Citation: Li-Hua C, Xu R-C, Qun W, Yun-Jun L, Wen-De L, et al. (2015) The Primary Large Fourth Ventricular Schwannoma Removed by the Cerebellomedullary Fissure Approach. Case Report and Review of the Literature. J Neurol Disord 3: 204. doi: $10.4172 / 2329-6895.1000204$

Page 3 of 9

watertight fashion. In order to ensure successful surgeries, practised and accurate technique is prerequisite.
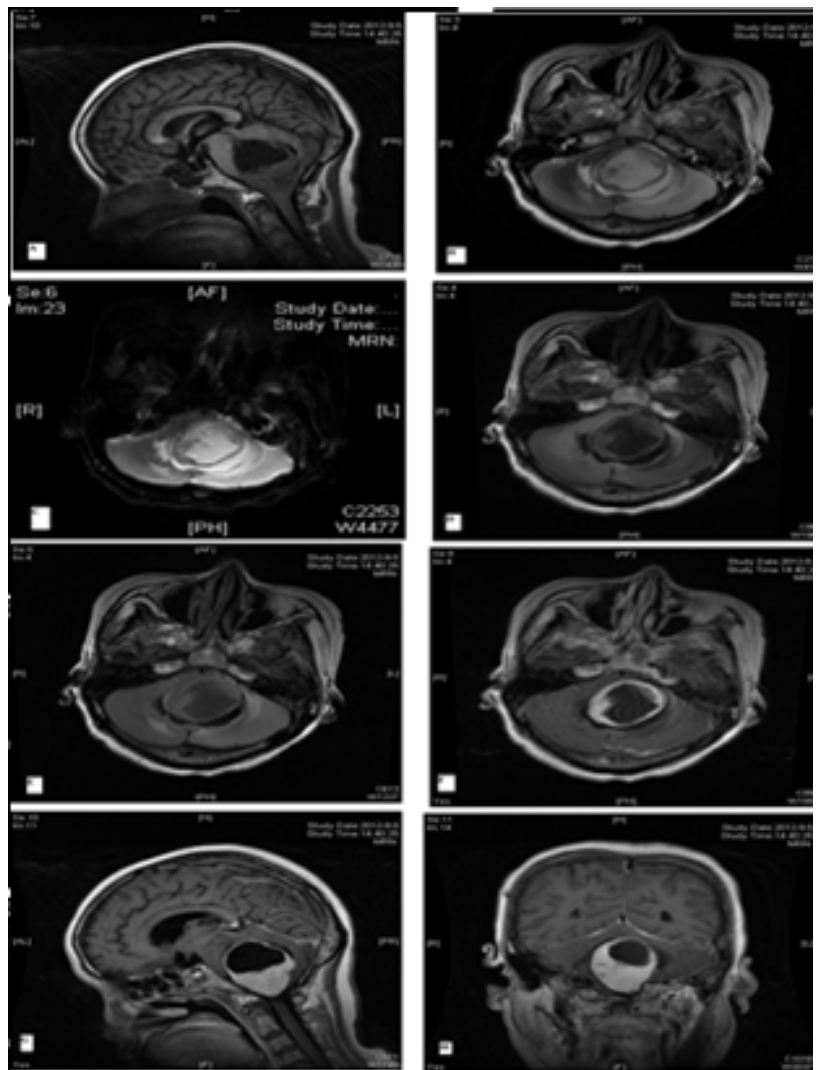

Figure 2: Pre-operative MR Image demonstrates large lesion located in the fourth ventricle, $5.1 \mathrm{~cm} \times 5.3 \mathrm{~cm}$ in size, demonstrating a heterogeneously enhancing. A tumor associated cyst is noted to extend across midline. (A) Sagittal T1-WI showing solid-cystic and mixed signal mass within the fourth ventricle, depicting how the tumor creates pressure on the brain stem. (B) T2-propeller axial radiological image showing asymmetrical hyperdense tumor located in the fourth ventricle with cerebellar hemisphere edema, and brain stem compressing to shift right side. (C) DWI sequence showing mixed hyperdense tumor with isodense tumor periphery. (D) T1-flair showing iso- to hypodense mass in the fourth ventricle, brain stem is out of shape and shifting to right side because of tumor compression. (E) T2-flair showing iso- to hyperdense mass with cerebellar hemisphere edema; $(\mathrm{F}, \mathrm{G}, \mathrm{H})$ axial, Sagittal and coronal pre-operative and Post-contrast MR images with gadolinium, preoperative gadolinium enhanced T1-WI in the axial (F), sagittal $(\mathrm{G})$ and coronal $(\mathrm{H})$ plane revealing a well-enhanced primary intraventricular schwannoma extending into the fourth ventricle. It is showing apparently circular enhancement lesion in the fourth ventricle, and a heterogeneous enhancement mass, tumor is well defined in $4^{\text {th }}$ ventricle with part of the tumor free in the cisterna magna. But cystic segment not enhancement.

\section{Intraoperative findings}

When the tumor was exposed, the xanthochromic fluid was present within the cyst. The solid portion of the tumor was tenacious obviously at the periphery segment of the tumor. it had a grayish white appearance with moderate vascularization. A plane was easily established around the tumor as it was internally debulked and intratumoral decompression, followed by microsurgical total excision of tumor. Tumor was well-encapsulated distinct from cerebral tissue, arising within the confines of the forth ventricle, but extending beyond it into adjacent white matter in the cerebellar areas (Figure 3A). At surgery, the tumor was relatively well circumscribed and had a good plane around it. The lesion was moderately vascular and easily bleeding, branches from PICA supplied the tumor, and PICA and its branches had been encased by tumor (Figure 3B). It was firm $n$ consistency but easily breakable and regular spherical mass, so that a complete macroscopic resection was achieved by debulking from the centre of the tumour in combination with progressive circumferential mobilization around its margins through microsurgical technique, and preservation of the surrounding neurovascular structures.

Dissection of the surgical specimen revealed that the tumor was completely located in the fourth ventricle and nowhere attached to any of the surrounding structure. The tumour did not have any attachment to the cranial nerves which were in the vicinity. It was also clearly free of the dura, the brain parenchyma and blood vessel around it or to the dura mater. The tumor was intimately adjoining the brainstem, nonetheless a total resection could be performed under cavitron ultrasonic aspiration (CUSA) and laser scalpel assistance.
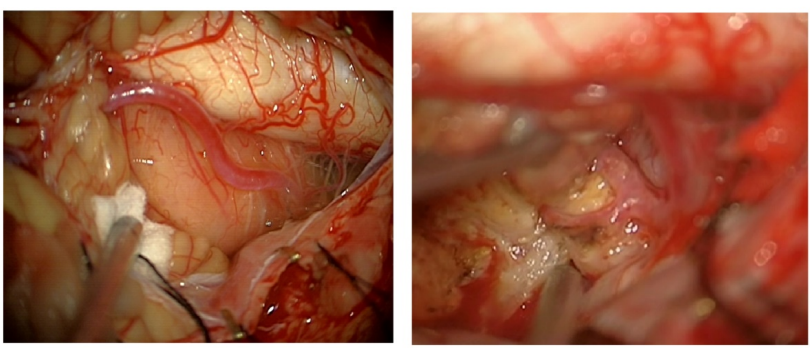

Figure 3: Intra-operative showing tumor is xanchromatic mass extending into cisterna magna. A. intra-operative showing brain stem shifting to right due to tumor compression. B, tumor encasing PICA and its branches.
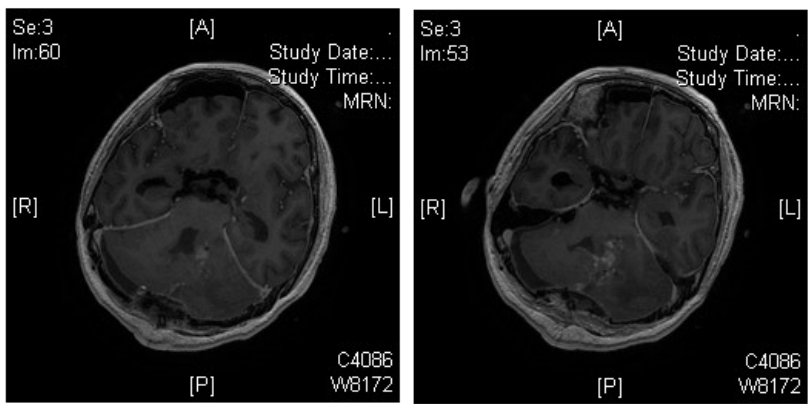

Figure 4: Intra-operative MR(T1-BRAVO subsequence) images with gadolinium showing tumor total removal, edema in the middle cerebellar peduncle on the left side. 
Citation: Li-Hua C, Xu R-C, Qun W, Yun-Jun L, Wen-De L, et al. (2015) The Primary Large Fourth Ventricular Schwannoma Removed by the Cerebellomedullary Fissure Approach. Case Report and Review of the Literature. J Neurol Disord 3: 204. doi: $10.4172 / 2329-6895.1000204$

Page 4 of 9

\section{Post-operative treatment}

Postoperative period was uneventful, the patient's diplopia resolved partially, his swallow disorders and cerebellar signs progressively improved such that he could ambulate without assistance, and he swallow semifluid food. However, the remaining neurological deficits, including her ataxia and facial paresis, were unchanged. He did not aggravate any hearing disturbance or lower cranial nerves symptoms like hoarseness or dysphagia and recovered well. Postoperatively he awoke without deficit, although his immediate course was complicated by a subgaleal CSF collection that the lumbar puncture drainage was performed 1 day after surgery, and the patient was discharged on postoperative day 17, and remains well. The patient recovered uneventfully but was left with his previous deficits and a left sided ataxia which has improved with physiotherapy. Final pathology revealed this lesion to be an intraventricular schwannoma. Intraoperative MRI (Figure 4), post-operative CT (Figure 5) and MR imaging proved total resection of the tumour with residual edema in middle cerebellar peduncle (Figure 6).

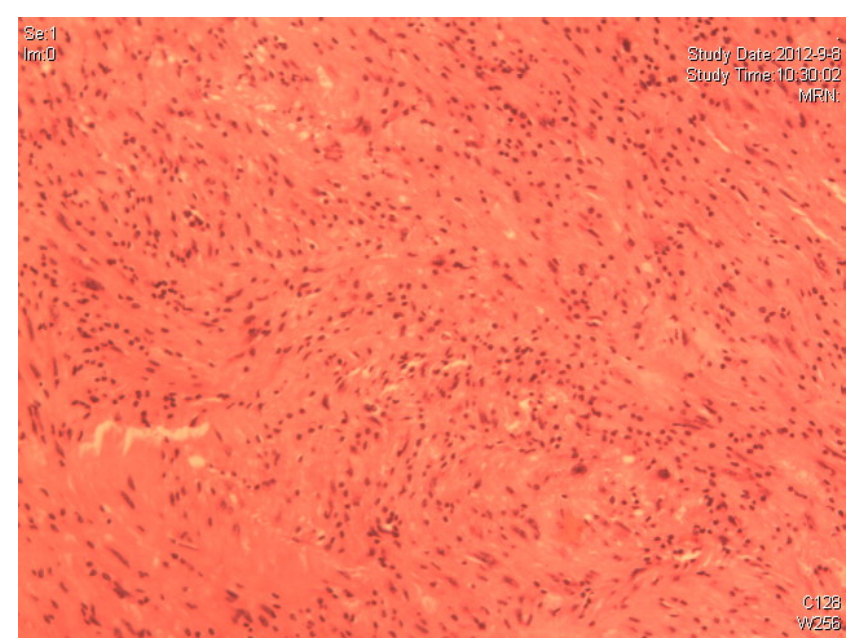

Figure 5: H\&E, $\times 20$. Proliferation of spindle-shaped cells, elongated and slightly pleomorphic nuclei with characteristic Antoni A areas (dense celullar sectors) and Antoni B areas (loose sectors).

\section{Histological examination}

Histological examination of the resected specimen was typical of schwannoma (Figure 7). Microscopic examination showed fascicles of spindle cells neoplasm characterized by Antoni A and Antoni B areas with Verocay bodies characteristic of schwannomas. The tumor cells are immunopositive for S-100 protein and glial fibrillary acidic protein (GFAP). Epithelial membrane antigen (EMA) and neurofilament protein stains were negative.

\section{Follow-up}

She has been followed up for over 8 months now, with clinical and neuropsychological evaluation, and she is doing very well, neurologically intact, and without radiographic evidence of tumor progression. Follow-up MRI in the local hospital showed no tumor growth in the region of the forth ventricle after 3 months following surgical resection. Although the patient remained asymptomatic except for facial palsy (H-B III grade), a right ventriculoperitoneal shunt was still keeped to treat the hydrocephalus.
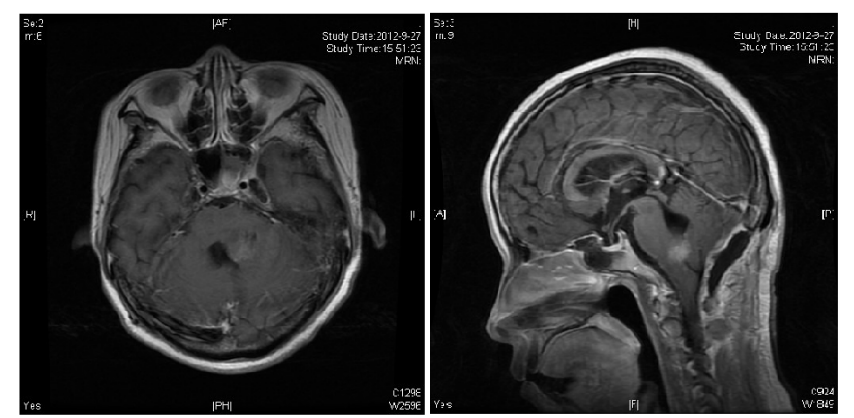

Figure 6: Post-operative axial and sagital MR image shows the resolution of the hydrocephalus and complete removal of the tumor. A, axial view T1-weighted MR images with gadolinium demonstrate no tumour, but complicating contusion in the middle cerebellar peduncle on left side. B, postoperative contrast-enhanced sagittal T1-WI MRI of the brain demonstrates shows no evidence of residual, and the fourth ventricle restoration.
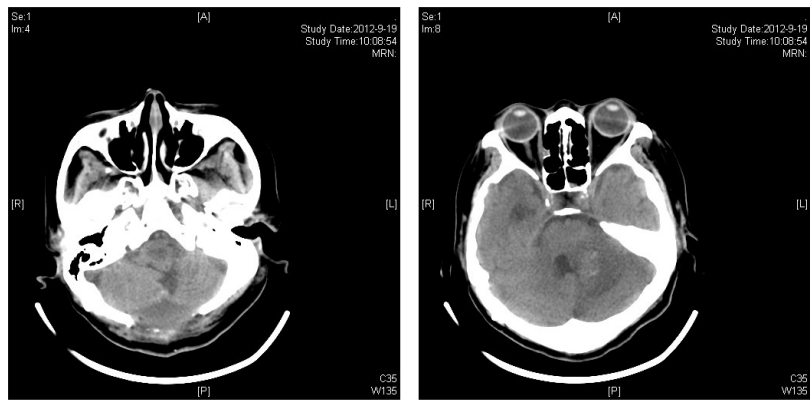

Figure 7: Postoperative non-enhanced CT scan, axial view, showing complete excision of tumor. A, showing the fourth ventricle and occipital bone defect after tumor resection; B, showing fourth ventricle and edema in the middle cerebellar peduncle on left side.

\section{Discussion}

\section{The clinical characteristic of intracranial schwannomas}

Intracranial schwannomas account for approximately $8 \%$ of all primary intracranial tumours, and are usually associated with cranial nerves [5,10,11,17,21,25-29]. Most originate from the vestibular portion of the CN VIII [21]. Others arise from the sensory fibers of cranial nerves V, VII, IX, X, and XI. It is rare to encounter a schwannoma within the brain parenchyma or ventricular system [10]. A variety of intraventricular tumours had be found nearly half a century, with the differential diagnosis depending upon the location in the ventricular system [7-9,30]. Intraventricular schwannomas are exceedingly rare. In 1957 Marchand et al. published the first case of an intraventricular Schwann cell tumor. This malignant schwannoma developed in the fourth ventricle in a 43-year-old man with schizophrenia [16]. David et al. [9] published the first case of a 
Citation: Li-Hua C, Xu R-C, Qun W, Yun-Jun L, Wen-De L, et al. (2015) The Primary Large Fourth Ventricular Schwannoma Removed by the Cerebellomedullary Fissure Approach. Case Report and Review of the Literature. J Neurol Disord 3: 204. doi: $10.4172 / 2329-6895.1000204$

Page 5 of 9

supratentorial intraventricular schwannoma in 1965. Since then, there are more 20 cases of pure intraventricular schwannomas in the literature, and the majority of these were located in the lateral $[5,7-17,19-21,23,24,31]$ descriptions are found in the literature. The vast majority of reported cases have been located in the lateral ventricle with only 8 cases in the fourth ventricle [5,12,16,21-24]. Intraventricular or intracranial schwannomas, which are not associated with the cranial nerves, can be regarded as ectopic schwannomas and account for less than $1 \%$ of surgically treated schwannomas of the central and peripheral nervous system [32]. Considering the unusual location of these tumors, immunohistochemical examination is crucial for the differential diagnosis. The S-100 protein is the diagnostic immunohistochemical marker for schwannoma. Most reported intraventricular schwannomas have been benign and amenable of successful surgical curatíve removal, without the need of any adjuvant therapy [7], with only four demonstrating invasive (malignant) features [14-17]. Jung [14] describe a case in which a malignant schwannoma was subtotally removed from the right lateral ventricle, with metastasis to both cerebellopontine angles and the cerebellum found 7 months later, it is the first report of an intraventricular malignant schwannoma with drop metastasis. Barbosa et al. described a case of cystic intraventricular schwannoma without recurrence for 10 years after resection [7].

Intraventricular schwannomas frequently present with short duration of signs and symptoms of increased intracranial pressure, focal neurological deficits. Their clinical presentation varies from incidental findings to symptoms of intracranial hypertension, resulting from mass effect or obstructive hydrocephalus, associated to headache, vomiting, papilledema and focal neurological deficits. The duration of symptoms varied from 2 weeks [8] to 40 years [13]. When reviewing the literature including the present case, the age distribution of patients with intraventricular schwannoma ranged from 7 [5] to 78 years [21]. In contrast to more typically located Schwann cell tumors, in the majority of instances intraventricular situated schwannomas tend to occur earlier in life and primarily in male patients. However, the present case itself differs from the majority of cases of intraventricular schwannoma reported in that our patient was a 53year-old female. In author opinion, the fourth intraventricular schwannomas do not appear to have a predilection for a particular age. MRI with and without gadolinium demonstrates a space-occupying lesion intimately related to the the forth ventricle with cystic degeneration or necrosis [33]. But, regardless of CT or MRI, a preoperative diagnosis is impossible. It is often not considered as the fourth ventricular schwannoma in the differential diagnosis due to the rarity of occurrence, and it lacks specific imaging characteristics to differentiate them from other intraventricular tumors [7-8,15,21]. For example, the differential diagnoses consisted of cystic astrocytoma ependymoma, hemangioblastoma, choroid plexus papilloma in our case. Even for the experienced neurological surgeon, the intraoperative diagnosis can be difficult as the tumor is not associated with any cranial nerves.

\section{The origin of intraventricular schwannomas}

Schwannomas are benign tumors of peripheral nerve sheath cells that originate from the myelin-forming Schwann cells at the Obersteiner-Redlich zone. They most commonly arise from the vestibular division of the CN VIII. Others arise from the sensory fibers of CN V, VII, IX and XI. Nerve fibers of the central nervous system are not invested with a Schwann cell covering. Therefore, the occurrence of a nerve sheath tumour in ventricle is unexpected $[7,10]$. The etiology of intraventricular schwannomas is not known and the origin is still controversial. The histological appearance of intraventricular schwannomas is similar to the commonly encountered extra-axial schwannomas, characteristically demonstrating spindle cell architecture with Antoni A and B areas. Despite this similar histological appearance, intraventricular schwannomas and extra-axial schwannomas may differ in their source of origin. It is well accepted that extraaxial schwannomas are derived from the myelinated cell of the peripheral nervous system. In contrast, nerve fibers of the central nervous system are not encased by a Schwann cell sheath; therefore, the occurrence of a schwannoma within the central nervous system is surprising. Interestingly, the exact source of origin for intraventricular schwannomas is currently not known, as there are several proposed etiopathogenic mechanisms. Several theories attempt to explain the origin of intraventricular schwannomas. At 1874, Benedickt [34] identified peripheral nerve fibers in the choroid plexus of the fourth ventricle, and confirmed by Stöhr in 1922 [35], suggesting that neoplastic transformation of these Schwann cells could result in an intraventricular schwannoma. Another theory proposes that intraventricular schwannomas originate from autonomic nerve fibers within the choroid plexus $[10,14,17,36]$. Because the autonomic nervous system is known to include Schwann cells [20], it appears most likely that primary intraventricular schwannomas arise from the autonomic nerve tissue of the choroid plexus $[8,9,11,14,15]$. Other proposed origins include neoplastic transformation of previously displaced neural crest cells during embryogenesis, differentiation of multipotent mesenchymal cells into Schwann cells, stem cells, and as these neural elements contain Schwann cells, neoplastic transformation is possible. $[5,8,11,12,14,16,19-21,24,37]$. Disordered embryogenesis and failed migration may be another origin of intraventricular schwannomas. Ectopic neural crest cells may deposit in the ventricle and undergo neoplastic transformation $[5,10]$. It has also been suggested that intra-axial schwannomas could arise from neural crest cells displaced into the nervous system as a result of failed migration in embryonic life [10]. This disordered embryogenesis theory may account for the relationship between intraventricular schwannomas and other neurocutaneous syndromes [8,11]. Schwann cells can be found in the perivascular nerve plexus that accompanies blood vessels into the central nervous system. Redekop et al. believed that their patient's fourth ventricular schwannoma could be explained by the theory of disordered neural crest cell migration with subsequent neoplastic transformation [5]. Riggs and Clary [38] postulated that these tumors could arise from proliferation of Schwann cells in perivascular plexuses. Prakash et al. [39] suggested misplaced myelinated nerve fibres as site of origin, while Ramamurthi et al. [40] suggested that these tumors could arise from neural crest cells displaced into the developing nervous system early in embryonic life. In our presented patient, it has radiographic, clinical, and intraoperative findings suggestive of tumor origin from Schwann cells within the superficial, intraparenchymal portions of the facial nerve, in the vicinity of the facial colliculus. We believe that the origin of the tumor in the present case is most easily explained by the theory that the neoplasm arose from schwann cells in the nerve root entry zone. The other possibilities being the origin from Schwann cells in the perivascular plexus or misplaced myelinated nerve fibers not attached to any of the cranial nerves [39]. Weiner [21] presented that two patients were confirmed both an intramedullary component arising from the floor of the fourth ventricle, as well as a posterior extension of the tumor into the fourth ventricle. The persistence of the 
Citation: Li-Hua C, Xu R-C, Qun W, Yun-Jun L, Wen-De L, et al. (2015) The Primary Large Fourth Ventricular Schwannoma Removed by the Cerebellomedullary Fissure Approach. Case Report and Review of the Literature. J Neurol Disord 3: 204. doi: $10.4172 / 2329-6895.1000204$

Page 6 of 9

hemifacial spasm may reflect the fact that vascular changes, lead to compression of the facial nerve at its root entry zone, causing hemifacial spasm.

On the basis of the varied clinical presentation of these tumors as reported in the literature, it has to be considered that the occurrence of intraventricular schwannoma may not be explained by a single theory alone and could be caused by several different and associated etiological mechanisms $[5,21]$. A single theory may not be sufficient to explain the occurrence of intraventricular schwannoma, it seems likely that several different mechanisms play a role $[5,21,32]$. Since nerve fibres of the central nervous system usually are not invested with a Schwann cell covering $[5,10]$, the occurrence of a nerve sheath tumor primarily in an intraventricular site as in the present case is highly uncommon. Theories of their origination include the peripheral or autonomic neural tissue within the choroid plexus or rests of neoplastic ectopic neural crest cells that have deposited in the ventricular system. Ross et al. [41] summarized the various theories proposed to explain the unexpected intramedullary location of these tumors. There are three theories explaining the origin of intraventricular schwannomas: (1) The neoplastic transformation of the perivascular autonomic neural tissue that contains Schwann cells, located in the intraventricular choroid plexus accompanying intrinsic arteries. This is supported by the identification of nerve fibers in the choroid plexus of the fourth ventricle by Benedickt in 1874 and St"ohr in 1922 [34,35]. Since autonomic nerves are invested with a Schwann cell covering, it is possible that intraventricular schwannomas may arise from neoplastic transformation of autonomic nervous tissue within the choroid plexus, thus contributing to the theories that assign its origin at the choroid plexus $[5,7,8,10,12-15,17,19-21]$. (2) An abnormal embryogenesis leading to a failed migration of the neural crest cells. Schwann cells are derived from the neural crest, and it is possible that a few of these cells could become trapped within the neural tube as it closes and undergoes differentiation during embryonic development. These neural crest cells may deposit in the ventricle, and neoplastic transformation of these Schwann cells could result in a schwannoma in an unusual location. This theory could explain why these tumors are so rare [5], and this would confirm a congenital origin of these tumours. (3) neoplastic growth of Schwann cells at the nerve root entry zone, the so-called 'critical area', where nerve roots lose their myelin sheaths upon penetrating the pia mater. Therefore, the current theories explaining the origin of these rare locations can only be considered as hypotheses.

\section{The clinical characteristics of the fourth intraventricular schwannomas}

Intraventricular schwannomas are rare, particularly originate from forth ventricle, only 8 cases located in fourth ventricles [5,12,16,21-23] in the literature. The clinical features of the forth ventricular schwannomas, including our case are sumarized in Table 1. This schwannoma has no age preference - from 7 to 78 , with an average of 49.8 years of age. Clinically, they more frequently present with short duration symptoms and signs of intracranial hypertension, with cranial nerves affected and motor and sensory deficits. Schwann cell tumors arising primarily within the ventricular system and predominantly or completely intraventricular in location have to be differentiated from intracranial extra- and intra-axial cerebral schwannomas with secondary invasion and extension into the ventricles and periventricular location. CT scan and MR could not reveal specific imaging characteristics, but it is useful in demonstrating these lesions, showing schwannoma features, and located precisely intraventricular mass lesions. For the differential diagnosis, the precise location of the mass inside the ventricle is of primordial importance. The finding of the fourth intraventricular schwannomas on CT scanning is iso-- or hyperdense and accompanying with the marked heterogeneous contrast enhancement. It is usually regular and a cystic component is frequent. MR imaging is the best diagnostic tool in these tumours because it demonstrates the intraventricular position and its relationship with the forth ventricle. In T1-WI, the tumour may show iso- or slightly hypointensity. In T2-WI, it usually has a mixed signal. Since these tumors are located within the fourth ventricle, a possible accompanying feature of these tumors is obstructive hydrocephalus $[16,21]$. While shunting of cerebrospinal fluid is reasonable, either temporarily with an external ventricular drain or permanently with an indwelling ventriculoperitoneal shunt, this was encountered in our patient.

However, in some cases it is difficult to differentiate radiographically or even histopathologically between intraparenchymal schwannoma with ventricular extension and intraventricular schwannoma with brain parenchyma invasion [7]. Most forth intraventricular schwannomas appeared as heterogeneously contrast enhancing mass lesions, with asymmetrical enhancement after contrast application in our case. The tumour appeared as a firm, well circumscribed yellow or witheish, easily bleeding mass, attached to the choroid plexus or the floor of the forth ventricle. The cyst may contain clear or xanthochromic fluid [5]. The most schwannomas of the fourth ventricle usually appeared to originate from the floor of the fourth ventricule [5,16,21-22], (Table 1). Weiner [21] presented the two patients schwannomas were clearly observed to arise from the floor of the fourth ventricle and, therefore, gross total resection could not be achieved. In the case described by Estrada Mastache et al. [12] and Oertel et al. [18], the tumor originated from the ventricle roof and extended into the fourth ventricle. In addition, surgical removal of these fourth ventricular tumors was curative with no need for further treatment.

\section{The microsurgical treatment of the forth ventricular schwannomas}

The optimal treatment of the forth ventricular schwannoma is microsurgical resection without having to resort to further adjuvant therapy. Complete resection is the therapeutic goal for this benign pathology to avoid recurrence [31]. Gradual or complete relief of clinical symptomatology without surgery-associated complications and recurrence was mostly achieved after judicious surgical resection [5,7-15,17,19-21]. Kachhara describe a very unusual case of schwannomas originating in lateral recess of the fourth ventricle [23]. Tumor was completely excised microsurgically via midline suboccipital craniectomy and C1 laminectomy. Long term outcome after excision is generally good [41]. But sometimes a complete removal has not been possible. Nevertheless, our experience suggests that every attempt should be made to acchieve a gross total resection of tumor, if possible, without damaging intrinsic brainstem structures. 
Citation: Li-Hua C, Xu R-C, Qun W, Yun-Jun L, Wen-De L, et al. (2015) The Primary Large Fourth Ventricular Schwannoma Removed by the Cerebellomedullary Fissure Approach. Case Report and Review of the Literature. J Neurol Disord 3: 204. doi: $10.4172 / 2329-6895.1000204$

Page 7 of 9

\begin{tabular}{|c|c|c|c|c|c|c|c|c|c|}
\hline Author /years & Age(yr)/ Sex & $\begin{array}{l}\text { Symptoms and } \\
\text { signs }\end{array}$ & Duration & Location & approach & $\begin{array}{l}\text { Surgical } \\
\text { removal }\end{array}$ & tumor origin & Result & $\begin{array}{l}\text { Follow-up } \\
\text { period }\end{array}$ \\
\hline $\begin{array}{l}\text { Marchand/ } \\
1957\end{array}$ & $43 / \mathrm{M}$ & $\begin{array}{l}\mathrm{H} / \\
\mathrm{A}, \text { schizophrenia }\end{array}$ & 4.4 years & V. IV & NS & NS & floor of V. IV & MS & $\begin{array}{l}\text { Died } \\
\text { (electroshock } \\
\text { therapy for } \\
\text { schizophrenia) }\end{array}$ \\
\hline Redekop/1990 & 7/M & $\begin{array}{l}\text { Bilateral OP, } \\
\text { nystagmus } \\
\text { dysdiadochokine } \\
\text { sia }\end{array}$ & 5 months & V. IV & M. SO & ST & floor of V. IV & $\begin{array}{l}\text { L. ataxia } \\
\text { unimproved }\end{array}$ & $\begin{array}{l}18 \text { months no } \\
\text { reccurence }\end{array}$ \\
\hline Weiner/1993 & $61 / \mathrm{M}$ & $\begin{array}{l}\mathrm{H} / \mathrm{A}, \mathrm{CS}, \mathrm{FP}, \mathrm{HS} \\
\text { neck pain }\end{array}$ & years & V. IV & MSC, C1-LE & ST & floor of V. IV & $\mathrm{HC}, \mathrm{BD}$ & NS \\
\hline & $78 / \mathrm{F}$ & $\begin{array}{l}\text { CS,FP,HS, } \\
\text { diplopia }\end{array}$ & 7 months & V.IV V & MSC, C1- LE & ST & floor of V. IV & improved & NS \\
\hline Estrada /200 & $36 / F$ & $\mathrm{H} / \mathrm{A}, \mathrm{CS}$ & 9 months & V. IV & MSC & T & roof of V. IV & $\begin{array}{l}\text { BD } \\
\text { unimproved }\end{array}$ & NS \\
\hline Oertel/2009 & $71 / \mathrm{F}$ & $\begin{array}{l}\text { episode } \\
\text { transient } \\
\text { scintillating } \\
\text { scotomas }\end{array}$ & 2 months & V. IV & MSC & T & roof of V. IV & uneventful & $\begin{array}{l}2.5 \text { years no } \\
\text { reccurence }\end{array}$ \\
\hline Hodges/2011 & 69/M & $\begin{array}{l}\text { worsening } \\
\text { generalized } \\
\text { weakness, } \\
\text { GI,MD }\end{array}$ & No & V. IV & $\begin{array}{l}\text { tonsillo- } \\
\text { nodular and } \\
\text { telovelar } \\
\text { approach }\end{array}$ & T & floor of V. IV & No & No \\
\hline $\begin{array}{l}\text { Kachhara/ } \\
2012\end{array}$ & $30 / \mathrm{M}$ & H/A, EG, L.CS & 5 months & $\begin{array}{l}\text { lateral recess } \\
\text { of } \mathrm{V} . \mathrm{I}\end{array}$ & MSC, C1-LE & T & NS & $\begin{array}{l}\text { edema, } \\
\text { L.CS }\end{array}$ & No \\
\hline $\begin{array}{l}\text { present case// } \\
2013\end{array}$ & $53 / F$ & $\begin{array}{l}\text { FP,CS,PE,ICH, } \\
\text { SD hoarseness }\end{array}$ & 4 months & $\begin{array}{l}\text { lateral recess } \\
\text { of } \mathrm{V} \text {. IV }\end{array}$ & TCMF & $\mathrm{T}$ & floor of V. IV & $\begin{array}{l}\text { edema,CS,F } \\
P\end{array}$ & $\begin{array}{l}8 \text { months no } \\
\text { recurrence }\end{array}$ \\
\hline
\end{tabular}

Table 1: Summary of 9 cases of primary forth intraventricular schwannoma reported in the literature: clinical and surgical features.

Tumors that are located in the fourth ventricles are always worrisome for the neurosurgeon, for access to this area is a challenging work and post-operative complications are usually inevitable. As reported in 8 other cases of fourth ventricular schwannomas, a midline suboccipital craniotomy was implemented for surgical access to the fourth ventricle schwannoma [5,12,21]. Conventional route of access to the fourth ventricle is through a section in the vermis. Tumours of the fourth ventricle, are generally resected by splitting of the vermis, a well-established approach, which may result in many complications such as ataxia [42,43], cerebellar mutism, staggering gait. It is also necessary to retract the cerebellar hemispheres to get access to a deeplocated tumour and this may cause some injuries [42,43]. To avoid such complications, the transcerebellomedullary fissure approach provides a good corridor to the fourth ventricle. The cerebellomedullary fissure approach as a corridor to reach the fourth ventricle that was first described by Matsushima et al. [44]. He was the first to make use of the microsurgical anatomy of the cerebellomedullary fissure and used this approach to get satisfactory results [44]. Subsequently, Kellogg and Piatt [45] and then Ziyal et al. [43] also reported successful application of this approach for tumors of the fourth ventricle. Since then, some other studies reported the successful use of this approach for different tumors of the fourth ventricle [46-48]. When possible, gross total resection is the treatment of choice, particularly if the lesion is causing mass effect, neurologic symptoms, or obstructive hydrocephalus.

The cerebellomedullary fissure is located between cerebellar tonsils and medulla oblongata. Lateral and rostral extensions of this fissure are cerebellomedullary and cerebellopontine cisterns respectively. Tela choroidea and inferior medullary vellum compose the floor of this fissure. The PICA pass through cerebellomedullary fissure and the vein of the cerebellomedullary fissure runs in the fissure toward the cerebellopontine angle and eventually drains into the superior petrosal sinus. The floor of the cerebellomedullary fissure composes the roof of the fourth ventricle [49]. The most important feeder artery was the vertebral artery and PICA, in contrast to the normal feeders of choroid plexus which are the anterior inferior cerebellar artery (AICA), PICA and superior cerebellar artery. The transcerebellomedullary fissure approach, which provides good exposure of the fourth ventricle without splitting the inferior vermis [50], has proven successful. This approach prevents the damage of transvermian access and the resulting cerebellar mutism in some cases [51]. We are also in favor of the applicability of the subtonsillar-transcerebellomedullary fissure approach which may be reached through the cerebellomedullary fissure and the lateral aspect of the fourth ventricle into the forth ventricular schwannoma, it was proved that this approach is suitable 
Citation: Li-Hua C, Xu R-C, Qun W, Yun-Jun L, Wen-De L, et al. (2015) The Primary Large Fourth Ventricular Schwannoma Removed by the Cerebellomedullary Fissure Approach. Case Report and Review of the Literature. J Neurol Disord 3: 204. doi: $10.4172 / 2329-6895.1000204$

Page 8 of 9

even for bulky tumours of the fourth ventricle with minimal destruction of important neural tissues. For optimum results, exquisite microneurosurgical techniques should be essential in order to effectively open the roof of the fourth ventricle and obtain a wide exposure of its interior.

\section{Conclusions}

In summary, fourth ventricular schwannomas are extremely rare; only eight cases have been described in the literature. Although their etio-pathologic origin is different from extra-axial schwannomas, their imaging, histology, ability to achieve a gross total resection and clinical course appear identical with other schwannomas and should be managed similarly. By reviewing the literature and analysing a personal case of the schwannoma originating within the forth ventricle, we presented that surgical excision is curative modalities of the primary fourth intraventricular schwannomas. Complete excision is the therapeutic objective for this benign tumour to prevent possibility of recurrence and the long-term prognosis is good. The transcerebellomedullary fissure approach provided a effective surgical exposure and practical operative approach to schwannoma of the fourth ventricle

\section{References}

1. Russell DS, Rubinstein LJ (1977) Pathology of tumours of the nervous system (4thedn.), Edward Arnold, London.

2. Zulch KJ, Braintumors (1986) Theirbiologyandpathology (3rdedn.), Springer-Verlag, Berlin,.

3. Bhatjiwale M, Gupta S (1999) Midline cerebellar cystic schwannoma: a case report. Neurol India 47: 127-129.

4. Ladouceur D, Bergeron D, Lamarche JB, Lamontagne L (1989) Cystic schwannoma of the brainstem. Can J Neurol Sci 16: 357-360.

5. Redekop G, Elisevich K, Gilbert J (1990) Fourth ventricular schwannoma. Case report. J Neurosurg 73: 777-781.

6. Whee SM, Lee JI, Kim JH (2002) Intrasellar schwannoma mimicking pituitary adenoma: a case report. J Korean Med Sci 17: 147-150.

7. Barbosa MD, Rebelo O, Barbosa P, Gonçalves J, Fernandes R (2001) Cystic intraventricular schwannoma: case report and review of the literature. Neurocirugia (Astur) 12: 56-60.

8. Benedict WJ Jr, Brown HG, Sivarajan G, Prabhu VC (2008) Intraventricular schwannoma in a 15 -year-old adolescent: a case report. Childs Nerv Syst 24: 529-532.

9. David M, Guyot JF, Ballivet J, Sachs M (1965) [Schwannoid tumor of the lateral ventricle]. Neurochirurgie 11: 578-581.

10. Dow GR, Hussein A, Robertson IJ (2004) Supratentorial intraventricular schwannoma. Br J Neurosurg 18: 561-562.

11. Erdogan E, Ongürü O, Bulakbasi N, Baysefer A, Gezen F, et al. (2003) Schwannoma of the lateral ventricle: eight-year follow-up and literature review. Minim Invasive Neurosurg 46: 50-53.

12. Estrada Mastache J, Sánchez Rodríguez G, Farías García R, Calderón Garcidue nas AL (2000) Schwannomadel cuarto ventrículo. Schwannomaof the fourth ventricle. Rev Med IMSS, 40: 405-408.

13. Ghatak NR, Norwood CW, Davis CH (1975) Intracerebral schwannoma. Surg Neurol 3: 45-47.

14. Jung JM, Shin HJ, Chi JG, Park IS, Kim ES, et al. (1995) Malignant intraventricular schwannoma. Case report. J Neurosurg 82: 121-124.

15. Lévêque M, Gilliard C, Godfraind C, Ruchoux MM, Gustin T (2007) [Intraventricular schwannoma: a case report]. Neurochirurgie 53: 383-386.

16. Marchand L, Koechlin P, Racine Y (1957) [Malignant Neurinoma Of The Fourth Ventricle With Intrabulbar Propagation In A Schizophrenic: Death During Electroshock]. Ann Med Psychol (Paris) 115: 108-113.
17. Messing-Jünger AM, Riemenschneider MJ, Reifenberger G (2006) A 21year-old female with a third ventricular tumor. Brain Pathol 16: 87-88, 93.

18. Oertel MF, Nolte KW, Blaum M, Weis J, Gilsbach JM, et al. (2009) Primary intraventricular schwannomas. Clin Neurol Neurosurg 111: 768-773.

19. Ost AH, Meyer R (1990) Cystic intraventricular schwannoma: a case report. AJNR Am J Neuroradiol 11: 1262-1264.

20. Pimentel J, Tavora L, Cristina ML, Antunes JA (1988) Intraventricular schwannoma. Childs Nerv Syst 4: 373-375.

21. Weiner HL, Zagzag D, Babu R, Weinreb HJ, Ransohoff J (1993) Schwannoma of the fourth ventricle presenting with hemifacial spasm. A report of two cases. J Neurooncol 15: 37-43.

22. Hodges TR, Karikari IO, Nimjee SM, Tibaleka J, Cummings TJ, et al. (2011) Fourth ventricular schwannoma: identical clinicopathologic features as schwann cell-derived schwannoma with unique etiopathologic origins. Case Report Med 2011: 165954.

23. Kachhara R, Raje P, Pauranik A (2012) Schwannoma originating in lateral recess of the fourth ventricle. Asian J Neurosurg 7: 151-153.

24. Oertel MF, Nolte KW, Blaum M, Weis J, Gilsbach JM, et al. (2009) Primary intraventricular schwannomas. Clin Neurol Neurosurg 111: 768-773.

25. Gibson AA, Hendrick EB, Conen PE (1966) Case reports. Intracerebral schwannoma. Report of a case. J Neurosurg 24: 552-557.

26. Gökay H, Izgi N, Barlas O, Erseven G (1984) Supratentorial intracerebral schwannomas. Surg Neurol 22: 69-72.

27. Hockley AD, Hendrick EB (1975) Unilateral proptosis and intracranial schwannoma. Surg Neurol 4: 509-512.

28. New PF (1972) Intracerebral schwannoma. Case report. J Neurosurg 36: 795-797.

29. Van Rensburg MJ, Proctor NS, Danziger J, Orelowitz MS (1975) Temporal lobe epilepsy due to an intracerebral Schwannoma: case report. J Neurol Neurosurg Psychiatry 38: 703-709.

30. Vasconcellos LP, Santos AR, Veiga JC, Schilemann I, Lancellotti CL (2009) Supratentorial intraventricular schwannoma of the choroid plexus. Arq Neuropsiquiatr 67: 1100-1102.

31. Jaimovich R, Jaimovich SG, Arakaki N, Sevlever G (2013) Supratentorial intraventricular solitary schwannoma. Case report and literature review. Childs Nerv Syst 29: 499-504.

32. Huang PP, Zagzag D, Benjamin V (1997) Intracranial schwannoma presenting as a subfrontal tumor: case report. Neurosurgery 40: 194-197.

33. Casadei GP, Komori T, Scheithauer BW, Miller GM, Parisi JE, et al. (1993) Intracranial parenchymal schwannoma. A clinicopathological and neuroimaging study of nine cases. J Neurosurg 79: 217-222.

34. Benedickt M (1874) Ueber die Innervation des Plexus choroideus. Virchows Arch Pathol Anat 59: 395-400.

35. Stöhr P (1929) Über die Innervation des Plexus choroideus des Menschen. Z Gesamte Anat(Ger) 63: 562-607.

36. Takahashi Y, Sugita Y, Abe T, Yuge T, Tokutomi T, et al. (2000) Intraventricular malignant triton tumour. Acta Neurochir (Wien) 142: 473-476.

37. Ahmad Z, Brown CM, Patel AK, Ryan AF, Ongkeko R, et al. (2010) Merlin knockdown in human Schwann cells: clues to vestibular schwannoma tumorigenesis. Otol Neurotol 31: 460-466.

38. Riggs He, Clary Wu (1957) A case of intramedullary sheath cell tumor of the spinal cord; consideration of vascular nerves as a source of origin. J Neuropathol Exp Neurol 16: 332-336.

39. Prakash B, Roy S, Tandon PN (1980) Schwannoma of the brain stem case report. J Neurosurg 53: 121-123.

40. Ramamurthi B, Anguli VC, Iyer CG (1958) A case of intramedullary neurinoma. J Neurol Neurosurg Psychiatry 21: 92-94.

41. Ross DA, Edwards MS, Wilson CB (1986) Intramedullary neurilemomas of the spinal cord: report of two cases and review of the literature. Neurosurgery 19: 458-464. 
Citation: Li-Hua C, Xu R-C, Qun W, Yun-Jun L, Wen-De L, et al. (2015) The Primary Large Fourth Ventricular Schwannoma Removed by the Cerebellomedullary Fissure Approach. Case Report and Review of the Literature. J Neurol Disord 3: 204. doi: 10.4172/2329-6895.1000204

Page 9 of 9

42. Mussi AC, Rhoton AL Jr (2000) Telovelar approach to the fourth ventricle: microsurgical anatomy. J Neurosurg 92: 812-823.

43. Ziyal IM, Sekhar LN, Salas E (1999) Subtonsillar-transcerebellomedullary approach to lesions involving the fourth ventricle, the cerebellomedullary fissure and the lateral brainstem. Br J Neurosurg 13: 276 - 284.

44. Matsushima T, Fukui M, Inoue T, Natori Y, Baba T, et al. (1992) Microsurgical and magnetic resonance imaging anatomy of the cerebellomedullary fissure and its application during fourth ventricle surgery. Neurosurgery 30: 325-330.

45. Kellogg JX, Piatt JH Jr (1997) Resection of fourth ventricle tumors without splitting the vermis: the cerebellomedullary fissure approach Pediatr Neurosurg 27: 28-33.

46. El-Bahy K (2005) Telovelar approach to the fourth ventricle: operative findings and results in 16 cases. Acta Neurochir (Wien) 147: 137-142.

47. Gök A, Alptekin M, Erkutlu I (2004) Surgical approach to the fourth ventricle cavity through the cerebellomedullary fissure. Neurosurg Rev 27: 50-54.
48. Sharifi G, Jahanbakhshi A, Sabeti S (2008) A large choroid plexus papilloma removed by the cerebellomedullary fissure approach. Case report and review of the literature. Turk Neurosurg 18: 302-306.

49. Jean WC, Abdel Aziz KM, Keller JT, van Loveren HR (2003) Subtonsillar approach to the foramen of Luschka: an anatomic and clinical study. Neurosurgery 52: 860-866.

50. Kawashima M, Matsushima T, Nakahara Y, Takase Y, Masuoka J, et al. (2009) Trans-cerebellomedullary fissure approach with special reference to lateral route. Neurosurg Rev 32: 457-464.

51. Shimoji K, Miyajima M, Karagiozov K, Yatomi K, Matsushima T, et al. (2009) Surgical considerations in fourth ventricular ependymoma with the transcerebellomedullary fissure approach in focus. Childs Nerv Syst 25: $1221-1228$. 